\title{
Active avoidance responding as a function of insulin-induced hypoglycemia
}

\author{
JERRY NEIDEFFER \\ Texas Christian University, Fort Worth, Texas 76129 \\ STEPHEN F. DAVIS \\ Emporia State University, Emporia, Kansas 66801 \\ and \\ MARY NELL TRAVIS-NEIDEFFER \\ Texas Christian University, Fort Worth, Texas 76129
}

\begin{abstract}
Two experiments investigating the effect of insulin-induced hypoglycemia (lowered bloodsugar level) on one-way active avoidance learning by rats are reported. The first study indicated that hypoglycemia resulted in significantly inferior avoidance acquisition. These results were replicated in the first phase of the second experiment. However, this acquisition deficit did not carry over to the second (retention) phase conducted $24 \mathrm{~h}$ later.
\end{abstract}

Moyer (1971) has stated that "hypoglycemia, from whatever cause, is, in many cases, associated with tendencies to hostility and is another dysfunction in the blood chemistry which evidently sensitizes the neural substrates for aggression. There has, unfortunately, been relatively little systematic study of this relationship" (p. 100). Subsequent field studies reported by Bolton (e.g., Bolton, 1973, 1976; Bolton \& Vadheim, 1973) have yielded considerable data supportive of this relationship. For example, Bolton (1973) reported a statistically significant correlation between hypoglycemia (lowered blood-sugar level), as measured by a 4-h glucose-tolerance test, and aggressiveness in a sample of the Qolla Indians of Peru and Bolivia. More specifically, a curvilinear function appeared best suited to describe the relationship. Additionally, Bolton (1976) reported a similar relationship between hypoglycemia and fantasied hostility in the Qolla.

Recently, a series of studies (Davis, Cronin, Meriwether, Neideffer, \& Travis-Neideffer, 1978; Davis, Gussetto, Tramill, Neideffer, \& Travis-Neideffer, 1978; Neideffer, Travis, Davis, Voorhees, \& Prytula, 1977) has sought to experimentally verify this relationship. The basic procedure used in these studies was to experimentally induce hypoglycemia in rats via insulin injection and then test the subjects in the single-animal shock-elicited aggression situation (see Azrin, Rubin, \& Hutchinson, 1968). The results of these studies have shown that (1) as insulin dose increased (i.e., hypoglycemia became more pronounced) the amount of attack and biting

Reprint requests should be sent to Stephen F. Davis, Department of Psychology, Emporia State University, Emporia, Kansas 66801. increased (Neideffer et al., 1977), (2) a curvilinear relationship appeared to exist between insulin dose and amount of attack and biting (Davis, Gussetto, Tramill, Neideffer, \& Travis-Neideffer, 1978), and (3) chronic insulin-injection procedures did not lead to habituation or adaptation of attack and biting (Davis, Cronin, Meriwether, Neideffer, \& Travis-Neideffer, 1978).

\section{EXPERIMENT 1}

As our initial studies have shown an increase in specific target-directed attack and biting, one-way active avoidance (which requires a specific response to avoid aversive stimulation) appeared to be a good situation in which to evaluate other possible effects produced by hypoglycemia.

\section{Method}

Subjects. Eighteen 120-day-old male albino rats purchased from the Holtzman Company, Madison, Wisconsin, served as subjects. All subjects were individually caged with food and water available on a free-feeding basis.

Apparatus. Testing took place in a Lafayette (Model 85204) one-way shuttlebox. In this apparatus, escape or avoidance is achieved by jumping to a safe compartment located $8.00 \mathrm{~cm}$ above the grid floor. A photoelectric beam was located $6.50 \mathrm{~cm}$ inside the opening of the safe compartment. Closure of an external switch activated a CS light located on one wall of the shock compartment and a Standard electric timer. A $1.50-\mathrm{mA}$ shock was automatically applied to the grid floor in the shock compartment $3 \mathrm{sec}$ following CS onset. Breaking the photoelectric beam in the safe compartment stopped the timer and terminated both the CS and shock application.

Procedure. Two equal $(n=9)$ groups (I-12 and C-12) were randomly formed prior to experimental testing. All animals received a 12-unit subcutaneous injection $1 \mathrm{~h}$ prior to testing. Subjects in Group I-12 were injected with U-40 regular zinc insulin (regular Iletin, Eli Lilly \& Company); subjects in 
Group C-12 were injected with $.06 \%$ phenol and served as an injection control group.

During testing, all subjects received 12 trials, with Trial 1 being administered to all subjects before Trial 2, and so forth. The order for running subjects was randomized at the beginning of the testing session. To run a trial, the experimenter removed the appropriate subject from the home cage and placed it in the shock compartment. As soon as the subject's feet touched the grid floor, the switch controlling the CS, shock application, and timer was closed. The subject was removed from the apparatus and returned to the home cage as soon as an escape or avoidance response was made. Response latencies were recorded for each subject for each trial.

\section{Results and Discussion}

Prior to analysis, all latencies were reciprocated to yield speed scores. Group mean escape and avoidance speeds are shown in Figure 1.

Analysis of variance of the speed data yielded significant groups $[F(1,16)=8.82, p<.01]$, trials $[F(11,176)=$ $3.18, \mathrm{p}<.01]$, and Groups by Trials interaction $[F(11,176)=2.02, p<.05]$ effects. Tukey's (a) procedure was used to further evaluate the significant interaction effect and indicated that Group $\mathrm{C}-12$ responded significantly faster on Trials $5(\mathrm{p}<.05)$ and $7-12$ $(p<.01)$. In order to evaluate possible weight-drug confounding, each subject was weighed just prior to receiving its injection. Analyses $\left(F_{\max }\right.$ and $t$ test $)$ of the data failed to yield significance.

The results of this study indicate that lowered bloodsugar level may interfere with the acquisition of one-way avoidance responding. It should also be noted that, even though the mean of Group I-12 did rise into the avoidance range, not all of the subjects in this group were avoiding by the end of training. However, the inferior performance shown by Group I-12 did not appear to be linked to increased activity and competing responses. Quite the opposite, these animals appeared less active than the injection controls, at least during CS presenta-

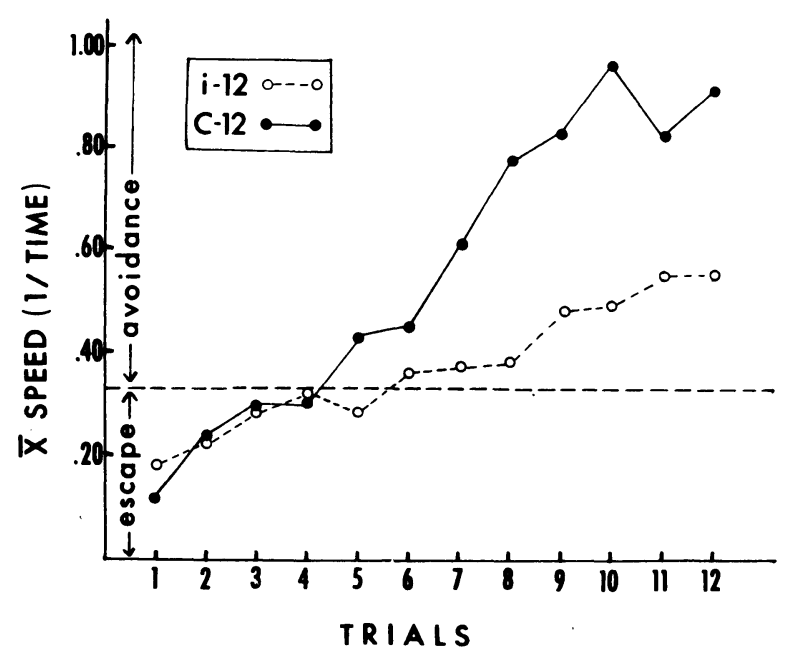

Figure 1. Mean escape/avoidance speeds, Experiment 1. tion. In fact, several subjects in Group I-12 required actual shock presentation before responding. In view of this, it would seem reasonable to speculate that the CS may have acquired little stimulus control over the behavior of Group I-12.

\section{EXPERIMENT 2}

If the inferior active avoidance acquisition shown by Group I-12 (Experiment 1) was in some manner due to a lack of attention to or conditioning of the CS, then it would seem reasonable to suggest that retention of this response might also be affected. Experiment 2 consisted of two phases, acquisition and retention, and was designed to investigate this possibility. The first phase essentially replicated Experiment 1 . The only difference was the addition of a group receiving a 9-unit insulin injection. This group was included in order to determine if the 12-unit dosage administered in Experiment 1 had a unique influence in producing the results. (The 12-unit dose had been shown by our previous research to produce the maximum amount of shock-elicited aggression in comparable animals.) During Phase 2 (retention), conducted $24 \mathrm{~h}$ later, all subjects received 12 additional active avoidance trials under reversed injection conditions.

\section{Method}

Subjects. Twenty-eight male 120-day-old Holtzman rats served as subjects. All subjects were housed and maintained as in Experiment 1.

Apparatus. The apparatus used in Experiment 1 was also used in Experiment 2.

Procedure. Prior to Phase 1 testing, three groups (9I, $n=7$; $12 \mathrm{I}, \mathrm{n}=7$; and $12 \mathrm{P}, \mathrm{n}=14$ ) were randomly formed. As in Experiment 1, all subjects received a subcutaneous injection $1 \mathrm{~h}$ prior to testing. Subjects in Groups 12P and 12I were injected with 12 units of $.06 \%$ phenol and U-40 regular zinc insulin (regular Iletin, Eli Lilly \& Company), respectively. Subjects in Group 9I received an injection consisting of 9 units of U-40 regular zinc insulin and 3 units of $.06 \%$ phenol. Thus, all injections were equated with regard to quantity injected. Phase 1 testing consisted of 12 active avoidance trials administered in the same manner as in Experiment 1.

Phase 2, administered $24 \mathrm{~h}$ later, consisted of 12 additional active avoidance trials. Prior to Phase 2, the subjects tested under phenol conditions in Phase 1 (i.e., Group 12P) were randomly assigned to one of two equal-sized $(n=7)$ groups. These groups were then randomly assigned to either the 9- or the 12-unit insulin-dosage condition. On the other hand, subjects tested under insulin-injection conditions in Phase 1 (i.e., Groups 9I and 12I) were injected with phenol prior to Phase 2 testing. As in Phase 1, all subjects received a 12-unit subcutaneous injection of phenol or $\mathrm{U}-40$ regular zinc insulin $1 \mathrm{~h}$ prior to testing.

\section{Results and Discussion}

Group mean escape and avoidance speeds ( $1 /$ time) for both phases are shown in Figure 2.

Phase 1. As analysis of variance performed on the speed data from Groups 9I and 12I failed to yield a significant difference $[F(1,12)=1.27, p<.25]$, the data for these two groups were pooled for further comparisons with Group 12P. This analysis yielded significant 


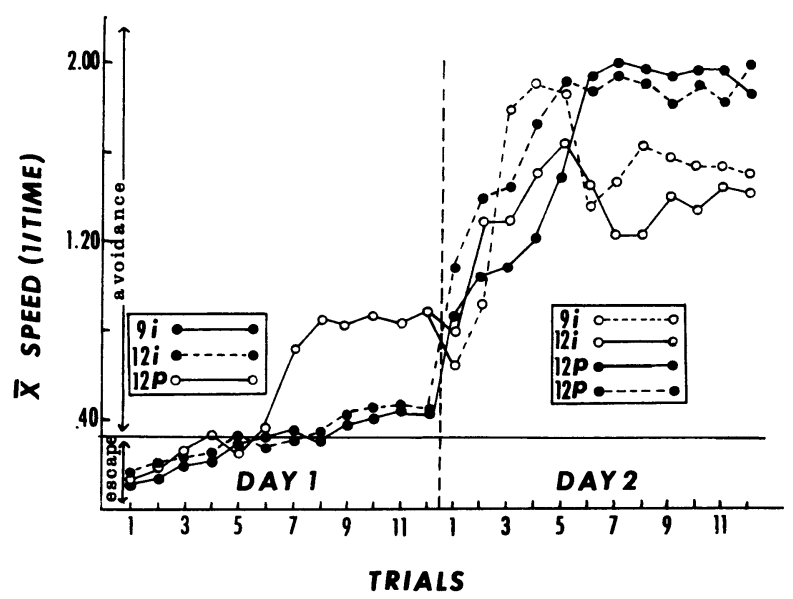

Figure 2. Mean escape/avoidance speeds, Experiment 2.

groups $[\mathrm{F}(1,12)=5.37, \mathrm{p}<.05]$, trials $[\mathrm{F}(11,286=1.95$, $\mathrm{p}<.05]$, and Groups by Trials interaction $[\mathrm{F}(11,286)=$ $3.03, \mathrm{p}<.01$ ] effects. Inspection of the significant interaction effect (Tukey's procedure) indicated that subjects in Group 12P were responding significantly $(\mathrm{p}<.01)$ faster than the insulin-injected subjects on Trials 7-12.

Phase 2. Analysis of variance of the Phase 2 speed data yielded significant groups $[\mathrm{F}(3,24)=3.57, \mathrm{p}<.05]$, trials $[F(11,264)=2.07, p<.05]$, and Groups by Trials interaction $[F(33,264)=2.79, p<.01]$ effects. Tukey's (a) procedure was used to inspect the significant interaction and indicated that the groups did not differ significantly on Trials 1,2 , and 5. On Trials 3 and 4 Group (12P)9I was avoiding significantly faster than Group (9I)12P. Both groups of phenol-injected subjects, Groups (9I) $12 \mathrm{P}$ and (12I)12P, avoided significantly $(p<.05)$ faster than $(1)$ both groups of insulin-injected subjects, Groups (12P)9I and (12P)12I on Trials 6, 7, 11 , and 12, and (2) Group (12P)12I on Trials 8,9, and 10.

As can be seen from Figure 2, the results of Phase 1 mirror those of Experiment 1; that is, superior active avoidance acquisition was shown by the injection control subjects (Group 12P). Again, several subjects in both insulin-injection groups (Groups $9 \mathrm{I}$ and 12I) failed to achieve avoidance by the end of Phase 1 training, and escape responding had to be prompted by shock applicaton.
The most striking result of Phase 2 was the rapid increase in avoidance speed shown by all groups. Thus, it would appear that the subjects initially trained under the insulin condition did learn something about the CS. This learning, however, was not manifested until Phase 2, when subjects were tested without the effect of the drug. On the other hand, the performance of the subjects shifted to the insulin condition on Day 2, indicating that once the avoidance response had been acquired it was not substantially disrupted by the introduction of the drug state. Obviously, two control groups, one receiving only insulin and one receiving only phenol during both phases of the experiment, might well have been included. However, the consistently high level of performance shown on Day 2 by the group shifted from insulin to phenol and the depression in performance shown toward the end of Day 2 by the subjects shifted from phenol to insulin suggests how these control groups might have performed.

\section{REFERENCES}

Azrin, N. H., Rubin, H. B., \& Hutchinson, R. R. Biting attack by rats in response to aversive shock. Journal of the Experimental Analysis of Behavior, 1968, 11, 633-639.

Bolton, R. Aggression and hypoglycemia among the Qolla: A study in psychobiological anthropology. Ethnology, 1973, 12, 227-257.

Bolton, R. Hostility in fantasy: A further test of the hypoglycemiaaggression hypothesis. Aggressive Behavior, 1976, 2, 257-274.

Bolton, R., \& VADHEim, C. The ecology of East African homicide. Behavior Science Notes, 1973, 8, 319-341.

Davis, S. F., Cronin, E. L., Meriwether, J. A., Neideffer, J., \& Travis-NeidefFer, M. N. Shock-elicited attack and biting as a function of chronic vs. acute insulin injection. Bulletin of the Psychonomic Society, 1978, 12, 149-151.

Davis, S. F., Gussetto, J. K., Tramill, J. L., Neideffer, J., \& Travis-Neideffer, M. N. The effects of extended insulin dosage on target-directed attack and biting elicited by tailshock. Bulletin of the Psychonomic Society, 1978, 12, 80-82.

MOYER, K. E. The physiology of hostility. Chicago: Markham, 1971.

Neideffer, J., Travis, M. N., Davis, S. F., Voorhees, J. W., \& Prytula, R. E. Sweet and sour rats: The effect of insulin dosage on shock-elicited aggression. Bulletin of the Psychonomic Society, 1977, 10, 311-312.

(Received for publication March 8, 1980.) 